\title{
Tornar-se mãe: Construindo o vínculo parento-filial na adoção tardia
}

\section{Becoming a Mother: Establishing the Parent-Child Bond in Late Adoption}

\section{Convertirse en madre: Construyendo el vínculo parento-filial en la adopción tardía}

\section{Débora Sampaio*}

Pontifícia Universidade Católica do Rio de Janeiro - PUC-Rio, Rio de Janeiro, Rio de Janeiro, Brasil

\section{Cristina Ribeiro Dantas**}

Pontifícia Universidade Católica do Rio de Janeiro - PUC-Rio, Rio de Janeiro, Rio de Janeiro, Brasil

\section{Andrea Seixas Magalhães***}

Pontifícia Universidade Católica do Rio de Janeiro - PUC-Rio, Rio de Janeiro, Rio de Janeiro, Brasil

\section{Terezinha Féres-Carneiro****}

Pontifícia Universidade Católica do Rio de Janeiro - PUC-Rio, Rio de Janeiro, Rio de Janeiro, Brasil

\begin{abstract}
RESUMO
Este estudo teve como objetivo investigara construção do vínculo parentofilial na adoção tardia. Foi realizado um estudo de caso, com base nos dados obtidos por meio de uma entrevista semiestruturada com uma mãe adotiva. Evidenciou-se a importância de a mãe se colocar disponível frente às necessidades da filha, permitindo que vivências anteriores à adoção fossem reparadas. A partir de uma leitura winnicottiana foi possível destacar que, assim como nos casos em que houve gestação biológica, os pais adotivos devem experienciar o estado de "preocupação materna primária", mesmo em momento tardio, oferecendo holding e funcionando como ambiente suficientemente bom para a criança. Constatou-se que mãe e filha se colocaram na relação, construindo o vínculo afetivo de forma mútua. 0 preparo dos pretendentes à adoção se mostrou essencial diante dos desafios do percurso de construção do vínculo parento-filial, sendo ressaltada a colaboração dos Grupos de Apoio à Adoção.
\end{abstract}

Palavras-chave: adoção tardia, preocupação materna primária, holding.

\section{ABSTRACT}

The purpose of this article was to investigate the establishment of the parent-child bond in late adoption. The authors conducted a case study 
based on data collected in a semi-structured interview with an adoptive mother. The researchers noted the importance of the mother showing herself available to face the needs of the child, allowing for experiences previous to the adoption to be repaired. By a Winnicottian approach, the authors highlighted that, same as in cases of biological gestation; adoptive parents must experience the state of primary maternal preoccupation, even if it happens late, offering a healthy holding environment for the child. The researchers also observed that mother and daughter placed themselves in the relationship, building an emotional bond in a mutual fashion. The preparation of aspiring adoptive parents was shown essential to face the challenges of establishing a parent-child bold, a path in which Adoption Support Groups also played an important supporting role.

Keywords: late adoption, primary maternal preoccupation, holding.

\begin{abstract}
RESUMEN
Este estudio tuvo como objetivo investigar la construcción del vínculo parento-filial en la adopción tardía. Fue realizado un estudio de caso, con base en los datos obtenidos a través de una entrevista semiestructurada con una madre adoptiva. Se evidenció la importancia de la madre hacerse disponible frente a las necesidades de la hija, permitiendo que vivencias anteriores a la adopción fuesen reparadas. A partir de una lectura winnicottiana fue posible destacar que, así como en los casos en que hubo gestación biológica, los padres adoptivos deben sentir el estado de "preocupación materna primaria", aunque en un momento tardío, ofreciendo "holding" y funcionando como ambiente suficientemente sano para el niño. Se constató que madre e hija se colocaron en la relación, construyendo un vínculo afectivo de forma mutua. La preparación de los pretendientes a la adopción se mostró esencial frente a los desafíos del recorrido de construcción del vínculo parento-filial, siendo resaltada la colaboración de los Grupos de Apoyo a la Adopción.
\end{abstract}

Palabras clave: adopción tardía, preocupación materna primaria, holding.

Entende-se por adoção tardia a adoção de crianças maiores de dois anos disponíveis no cadastro nacional de adoção. O termo "tardio", por si só, traz uma conotação daquilo que possa ter "passado do tempo" e este fato aponta para as especificidades desse tipo de adoção.

Ao iniciar o processo de adoção legal, o pretendente passa por inúmeros procedimentos burocráticos necessários. $O$ pedido deve ser formulado e encaminhado ao Juiz da Infância e Juventude da região, juntamente com documentos e o perfil traçado da criança ou adolescente que pretende adotar com informações dentre as quais estão: sexo, idade, cor de pele, e outras. Cabe destacar que o interesse dos brasileiros candidatos à adoção é, sobretudo, por bebês, de pele clara e do sexo feminino (Peiter, 2011). Machado, Féres-Carneiro e Magalhães (2015) sugerem que a definição do perfil da criança adotada representa também a busca por uma identificação pelo semelhante, fundamental para a construção do senso de pertencimento. 
Após a entrada no cadastro nacional da adoção, inicia-se a espera que pode ser experienciada como uma gravidez, com a ressalva de que não se sabe ao certo quanto tempo ela durará. $O$ que se sabe é que o tempo varia de acordo com o perfil escolhido pelo pretendente (Silva, 2018).

Quando uma criança, dentro do perfil escolhido, se encontra disponível na fila do cadastro, o telefone finalmente toca. Os pretendentes são comunicados sobre a criança e inicia-se o período de aproximação, levando ao estágio de convivência. Este momento é considerado fundamental para o estabelecimento do vínculo parentofilial. Ressaltamos, em consonância com Eboli, Santos, Carvalho e Pasian (2015), a importância do processo de seleção, preparo e acompanhamento psicológico dos pais adotivos, para que os filhos sejam inseridos em um ambiente capaz de protegê-los e garantir suas necessidades afetivas.

A adoção representa a possibilidade da reconstrução do ambiente que outrora fora perdido para a criança. A separação da família de origem pode ocorrer por diversos fatores como negligência, impossibilidade de oferecer o cuidado necessário ou o abandono propriamente dito. Por parte da criança, houve, necessariamente, uma experiência de ruptura com os laços biológicos, na maioria dos casos, em um momento bastante precoce. O abandono e o desamparo podem ficar marcados no psiquismo como um trauma, com maiores ou menores proporções, de acordo com as condições que envolveram a separação (Levinzon, 2018).

Winnicott (2016/1987) postula que os pais adotivos podem exercer uma espécie de função terapêutica com o intuito de promover a recuperação da criança das privações sofridas no passado. O conceito de de privação em Winnicott nos ajuda a compreender este cenário e diz respeito à perda de algo positivo que fez parte da experiência do bebê até determinado momento, mas que, no entanto, foi retirado. Desta forma, o desafio está em oferecer um ambiente seguro e estável, capaz de favorecer o desenvolvimento emocional da criança, sem descartar sua história pregressa (Otuka, Scorsolini-Comin, \& Santos, 2012).

A bagagem trazida pela criança aparece como uma das especificidades da adoção tardia. Desse modo, o respeito pelas experiências anteriores da criança adotada é prerrogativa para que o passado possa ser ressignificado (Sampaio, Magalhães, \& FéresCarneiro, 2018). Reflexos dessa história e marcas psíquicas geradas pelo abandono poderão repercutir na construção de novos vínculos. Ozoux-Teffaine (2004) discorre a respeito da desilusão estruturante no momento inicial da adoção, marcada, muitas vezes, por atitudes agressivas vindas da criança. Durante essa fase, é de suma importância que a família adotante não se deixe ferir em sua capacidade parental. Nesse momento, torna-se fundamental que os 
pais consigam suportar as tensões, a agressividade, a hostilidade e 0 silêncio, provenientes da criança, contendo e sendo depositários das memórias dela. Tal capacidade promove a regressão infantil necessária, possibilitando à criança, em um momento posterior, criar laços afetivos com seus pais adotivos.

As relações humanas, principalmente as primordiais, são de suma importância para a construção do self. A palavra self é utilizada por Winnicott (1960) para se referir à pessoa em sua essência, uma totalidade que é desenvolvida dentro de um processo maturacional. 0 bebê possui capacidades inatas para se desenvolver, mas ainda tem um ego frágil, carente dos cuidados da mãe ou de quem exerça tais cuidados. A empatia, a intuição inconsciente e a comunicação silenciosa entre mãe e bebê conduzem esse processo de holding ou sustentação, que permitirá ao bebê alcançar o sentimento de coesão e de um ser unitário (Levinzon, 2018).

Os pais serão como um continente estável, passível de dar continuidade à história da criança, auxiliando seus filhos na elaboração de suas ansiedades infantis. Caso isso não ocorra, a vivência traumática referente ao passado da criança pode não encontrar amparo para ser elaborada (Levy \& Bittencout, 2013).

Segundo Weber (1996), o medo da repetição da experiência de abandono pode estar subjacente ao comportamento agressivo do filho adotado, que, para testar o novo ambiente passa a demonstrar ódio ao invés de amor. O ódio se faz necessário na relação para que a criança possa testar o ambiente e, com isso, alcançar a certeza de que será amada e acolhida, desenvolvendo, por conseguinte, sua capacidade de amar (Gomes, 2006). De acordo com Winnicott (2001/1965), as expressões de ódio, raiva e agressividade direcionadas aos pais adotivos podem ser compreendidas como sinais de esperança e recuperação da criança em relação à sua existência e busca pelo pertencimento.

Para Otuka et al.(2012), na adoção suficientemente boa, pais e filhos se transformam, se conhecem e se identificam ao assumirem posições que favorecem a construção, em conjunto, de um ambiente saudável. Assim, a família adotiva, além de ser capaz de receber e conter as angústias arcaicas e as fantasias destrutivas do filho adotivo pode promover transformações em todos os membros da família, contribuindo para a criação de laços afetivos seguros e duradouros.

Nota-se que um dos maiores desafios da família adotiva será oferecer para a criança um ambiente suficientemente bom, capaz de atender às necessidades, na medida em que elas surgem, ou seja, oferecendo o holding necessário para que a criança experimente a continuidade da existência e possa se desenvolver. Isso implica em se fazer presente afetivamente, respeitando o tempo e o espaço da criança, permitindo-Ihe desenvolver juntamente com os novos pais e com 0 
ambiente uma confiança básica, viabilizando a construção de novos vínculos afetivos (Verceze, Silva, Oliveira, \& Sei, 2015). Para que os pais sejam capazes de oferecer o holding, faz-se necessário assumir certo estado de atenção, o qual pode ser relacionado ao conceito de "preocupação materna primária", cunhado por Winnicott (2000/1956), no qual a mãe é capaz de se colocar no lugar do seu bebê para atender às necessidades emocionais dele.

$\mathrm{Na}$ adoção, o período de preocupação materna primária será possível a partir da gestação simbólica, como assinalado por Gomes e Levy (2016), um período de "gravidez psíquica". Este se torna um momento fundamental para elaborações a respeito da adoção, possibilitando aos pais sonharem e refletirem sobre a parentalidade. Com isso, destaca-se o período de preparação para a chegada do filho adotivo como um momento-chave para o bom andamento do processo de vinculação parento-filial.

Ademais, levando em consideração que a adoção se dá em uma via de mão dupla, a criança também precisa adotar a nova família. Levy e Bittencourt (2013) destacam que a criança precisa elaborar o luto pela mãe biológica e renunciar ao retorno dela para, somente então, permitir o investimento na família adotiva. As autoras assinalam, ainda, que a idealização dos pais biológicos feita pela criança funciona como defesa frente ao abandono e pode culminar em fantasias que a ajudam a não sucumbir à angústia. Quando o trabalho de luto não pode ser realizado, cristaliza-se uma idealização parental e a criança se agarra a um amor idealizado para dar conta da espera frustrada (Levy \& Gomes, 2017).

Diante desse contexto, o objetivo deste trabalho foi investigar, a partir de um caso de adoção tardia, como o vínculo parento-filial foi sendo instaurado na medida em que a mãe se colocou disponível para reconstruir o ambiente familiar da criança. Buscou-se verificar, a partir da teoria winicottiana, como a adoção pode representar o caminho para a vivência dessa reparação, destacando os conceitos de preocupação materna primária, holding e mãe suficientemente boa, como essenciais para a compreensão desse processo de adoção mútua.

\section{Método}

Trata-se de estudo qualitativo, parte de uma pesquisa mais ampla sobre a construção do vínculo parento-filial nas adoções tardias. Foram entrevistados 10 sujeitos independentes, três homens e sete mulheres, que adotaram crianças maiores de dois anos. $O$ presente trabalho constitui-se num estudo de caso para o qual foi selecionada uma das entrevistas. Tal escolha se deu a partir da riqueza de dados obtidos na entrevista relativos à construção do vínculo parento-filial. 
Os dados da entrevista selecionada foram submetidos ao método de estudo de caso, em sua vertente instrumental (Stake, 2016). Embora essa estratégia metodológica se limite na extensão casuística investigada, permite uma maior compreensão acerca do fenômeno estudado, capturando suas características únicas ao mesmo tempo em que possibilita uma análise pormenorizada e ampla do objeto estudado. Nesse sentido, o estudo de caso torna-se uma estratégia metodológica profícua, permitindo que o fenômeno seja abordado em profundidade.

A opção pelo estudo de caso enquadra-se na abordagem teórica para interpretação dos dados: a psicanálise, mais especificamente utilizando-se do referencial winnicottiano. Nessa concepção teórica, é valorizado o que há de singular, em cada experiência, com foco nas relações intersubjetivas para interpretar o fenômeno (Otuka et al., 2012).

\section{Participante}

Para alcançar os objetivos deste estudo foi entrevistada uma mulher, com idade de 37 anos, solteira, com ensino superior completo, Julia. Foi critério de ter adotado uma criança maior de dois anos, há no mínimo seis meses, configurando uma adoção tardia. Julia adotou Ana aos dois anos e seis meses de idade. Ambos os nomes são fictícios. Por ocasião da entrevista, Ana tinha seis anos e o processo de adoção estava concluído.

\section{Instrumentos}

Como instrumento de investigação utilizou-se uma ficha biográfica com questões relativas à idade do participante; escolaridade; ocupação; religião; estado civil; configuração familiar; tempo de efetivação da adoção; idade da criança atual e por ocasião da adoção; com ou sem filhos biológicos. Além disto, foi realizada uma entrevista individual com roteiro semiestruturado, determinado a partir dos objetivos da pesquisa mais ampla, contendo questões abertas, compostas pelos seguintes eixos temáticos: motivação para a adoção tardia; vivências anteriores; familiares e rede; experiências subjetivas da parentalidade; experiência da construção do vínculo; e fantasias relacionadas ao filho imaginado.

\section{Procedimento}

O recrutamento da participante se deu a partir do contato informal da pesquisadora com grupos de adoção em sua rede social por meio da internet. A entrevista foi realizada em local de sua preferência, 
gravada em áudio e posteriormente transcrita na íntegra, para posterior análise.

O projeto que deu origem à pesquisa foi aprovado pelo Comitê de Ética em Pesquisa da instituição onde foi desenvolvida. Após a autorização, a participante assinou o Termo de Consentimento Livre e Esclarecido.

\section{Resultados e discussão}

Julia tinha 37 anos e era solteira quando decidiu adotar uma criança. Relata que seu desejo de ter filho surgiu em um momento muito frustrante de sua vida no qual reinou uma pergunta crucial: "Seu maior sonho é ser mãe ou ser esposa?". Tal questionamento veio de sua mãe, fazendo com que essa decisão adquirisse um peso ainda maior.

Diante da indagação de sua mãe, Julia chegou à conclusão de que seu maior sonho era ser mãe e, por razões religiosas, optou pela adoção. A partir de então, passou a frequentar Grupos de Apoio à Adoção e apadrinhou uma criança antes de dar entrada ao processo. Essa experiência fez aumentar em Julia o desejo pela adoção.

É importante destacar que o período que antecede a adoção se faz importante para o desdobramento dos acontecimentos. Pesquisas apontam para a necessidade de preparação e suporte oferecido às famílias que pretendem adotar (Eboli et al., 2015; Gondim, et al., 2008; Levy \& Bittencourt, 2013; Machado et al., 2017). Destaca-se o papel dos grupos de apoio à adoção nesse período. Para Sequeira e Stella (2014), uma das funções do grupo de apoio à adoção é promover a desidealização dos pais em torno da adoção, sensibilizando-os para as possíveis questões, conflitos e dificuldades que poderão surgir a partir da adoção.

O período de preparação é fundamental para ajudar no reconhecimento das reais motivações dos candidatos à adoção. A literatura mostra que, quando os pais não são suficientemente preparados, há o risco da comparação entre o "filho fantasiado" e o "filho real", o que pode gerar frustração no projeto altruísta e levar a depositar o insucesso da adoção na criança. Além disso, a preparação deficitária, tanto para a criança quanto para o candidato, dificulta o processo de construção do vínculo parento-filial, o que pode gerar o sentimento de fracasso em ambos os envolvidos (Levy \& Bittencourt, 2013). Nesse sentido, a reflexão acerca das reais motivações e crenças que levaram à adoção torna-se fundamental, visando ao reconhecimento e à diminuição das expectativas irreais, assim como as idealizações que perpassariam e poderiam dificultar o processo de espera para a adoção (Morelli, Scorsolini-Comin, \& Santeiro, 2015). 
Durante esse período inicial de preparação para a entrada no processo de adoção em si, o pretendente se depara com a escolha do perfil, solicitado pela Vara da Infância. Julia optou por uma criança entre dois e seis anos, configurando adoção tardia. Segundo ela, essa escolha se deu, sobretudo, por não desejar tanto um bebê, além de ter pressa pela chegada de sua filha. Em suas palavras:

Então, eu falei assim: "Se for gerado não tem opção, não tem como pular a fase do bebê". Mas eu falei assim: "Pra que eu ficar quatro, cinco anos numa fila, se é algo que eu quero pra ontem"... Só pra ter um bebê, que nem é algo que me atraia tanto?

Nota-se que Julia optou de imediato pela adoção tardia, o que aponta para a conscientização e mudança de paradigma quanto à escolha do perfil. Julia recebeu o telefonema da Vara da Infância falando sobre Ana, uma menina de dois anos e meio e, a partir de então, iniciou-se o processo de aproximação das duas. Ela conta que o período de adaptação não foi nada fácil. Julia passou a visitar o abrigo todos os dias durante um mês e meio durante esse período, Ana se mostrava arredia e não permanecia sozinha com Julia, denotando receio por essa nova aproximação:

E aí ficava lá uma média de duas horas e ela não queria ficar (risos). Aí a assistente social de lá falava: "Você tem que ficar sozinha com ela!" E ela não queria ficar de jeito nenhum, só chorava, chorava, chorava, chorava... Aí quando juntava com as outras crianças ela ficava meio que assim, me testando, entendeu? E aí comecei a levar coisas pra lá, então eu levei massinha, levei pintura... Foi um período difícil lá. Tanto que eu falava: "Mãe, ela não vai me amar!" (risos).

Aqui se iniciou um período crucial. Essa fase de estabelecimento do contato pode ser compreendida de forma análoga ao período de gestação. Gomes e Levy (2016) fazem referência a esse momento como "gravidez psíquica" que funciona como um período de espera e propício para elaborações a respeito do filho imaginado e a criança real a ser adotada. Assim, a gestação simbólica de uma criança diz respeito à capacidade dos pais de sonhar, imaginar e pensar sobre a parentalidade adotiva (Morelli et al., 2015).

Rossato e Falcke (2017) assinalam que a adoção de uma criança se assemelha à gestação biológica na medida em que também necessita de preparação do sistema para a chegada de um filho e da capacidade subjetiva dos pais de poderem imaginá-lo. Nesse contexto, os pais adotivos precisam construir a parentalidade, 
entrando em contato com suas motivações, medos e fantasias acerca da adoção.

Ao mencionar o choro contínuo e a 'testagem' realizada por Ana, Julia consegue criar um espaço entre as duas em que Ana se sente confiante para expressar seus medos e inseguranças. Para Winnicott (1947), muitas vezes, o que a criança procura é a legitimação do ódio e, quando não encontra espaço para expressá-lo, poderá se sentir incapaz de alcançar o amor. Nesta perspectiva, o autor assinala que as crianças vindas de lares desfeitos vivem em busca, mesmo que inconscientemente, dos pais. Essa testagem faz parte do processo de vinculação. Por isso, deve ser considerada como algo estruturante no processo de filiação e não como algo destrutivo.

Ademais, a parentalidade adotiva preconiza a existência de um processo de adaptação e elaboração psíquica de todos os membros da família. Julia conta como toda a família se organizou e se mobilizou diante da adoção, oferecendo suporte para a chegada desse filho sonhado:

Todos ficaram encantados! [...] E todos abraçaram; meu irmão, meu pai, primos. Choraram quando eu ia no período de aproximação, né? Das minhas angústias. Então todo mundo abraçou sem questionar.

Ser recebido no mundo pelo cuidador é uma necessidade fundamental para o sujeito. A constituição subjetiva acontece, sobretudo, através de um outro e do cuidado que esse outro oferece. Essa recepção marca o pertencimento à família, à comunidade, além de estabelecer o ethos (Safra, 2004). Assim, as figuras dos cuidadores são de extrema importância para realizar o acolhimento do bebê e apresentá-lo ao mundo. Isso se dará segundo as peculiaridades de cada família, configurando a singularidade desse bebê. Na história de Ana, sua chegada foi comemorada por todos os membros da família. Winnicott (1997/1955) caracteriza a adoção como uma experiência positiva, podendo ser uma prática bemsucedida, na medida em que a família adotante possa se posicionar como suficientemente boa para a criança adotada.

Julia descreve o modo como aos poucos o vínculo foi sendo criado e, mesmo se mostrando desconfiada, como Ana permanecia atenta e conectada a essa nova construção:

Então, tipo assim, ela queria criar um laço, né? Mas tinha medo. Olha só, sabe, vamos passear! Aí ela ficava né? Não me chamava de mãe, mal me chamava de tia, aliás, ela mal falava, na verdade... A cumplicidade foi vindo mais pelos olhares dela. E aí eu soube, quando ela voltava pra lá, junto da faixa etária dela, as cuidadoras perguntavam... Quem veio visitar? E aí um 
dia elas me falaram que ela falava que era a mãe. Aí eu disse: "Bom, então tá criando, ela tá entendendo, né? Eu não tô tão uma pessoa qualquer".

Nessa fala, nota-se que o vínculo afetivo na adoção, como todos os outros, se dá de forma mútua, sendo construído no dia a dia. A cumplicidade entre mãe e filha foi sendo constituída a partir do olhar da filha para a mãe, em uma comunicação que pertencia a ambas. Segundo Dolto (2008/1977), a criança também adota seus pais. Muitas vezes, a ansiedade para que o vínculo seja criado instantaneamente pode dificultar o seu estabelecimento. Desta forma, sobretudo por se tratar de adoção tardia, a criança irá demarcar esse limite em relação aos pais para demonstrar que esse vínculo acontecerá a partir deum encontro mútuo que exige atenção e paciência.

A disponibilidade da criança para a construção de vínculos afetivos pode ser percebida. Embora, em um primeiro momento, ocorra certa desconfiança que se revela a partir do temor de um novo abandono (Orionte \& Souza, 2005). No relato de Julia foi possível notar sua disponibilidade diante dessa construção, se colocando de forma compreensiva quanto às necessidades de Ana, acolhendo-a e sendo continente, ou seja, de acordo com Winnicott (1990/1962), funcionando como mãe-ambiente e oferecendo o holding necessário.

Ressalta-se que essa mãe-ambiente não necessariamente é aquela que gesta a criança. É necessário que haja identificação com a mãe. Nesse sentido, na adoção também é importante haver identificação e sensibilidade em relação a esta criança para que suas necessidades possam ser atendidas. Na fala a seguir é possível perceber como Julia foi se adaptando às necessidades de Ana, acolhendo-as e se colocando disponível:

Aí depois teve a regressão né? "Me ajuda, não sei fazer, não sei o quê", nada mais fazia sozinha... Não chegou bebê, então não dá pra tratar como bebê. Mas quis mamar no meu peito, eu falei assim: "Mas não sai leite!(risos) nem você tem mais idade pra isso". "Ah, mas eu quero!". Não adianta, eu deixei, aí falou: "Não sai". Aí eu: "Pois é, não sai". Falei assim: "Você quer beber seu leite no copinho, na posição?" "Ah, quero!" Aí botei ela deitadinha, como se realmente tivesse sendo amamentada, mas no copinho, que nem na mamadeira ela bebia mais.

Mesmo se tratando de adoção de criança maior, cabe assinalar que a mãe que recebe essa criança recebe também o bebê que a constitui. Na maioria das vezes, ocorre regressão por parte da criança adotada, abrindo a possibilidade para a revivescência de momentos anteriores da infância. Levy e Bittencourt (2013) destacam que a fase inicial de 
inscrição da filiação é marcada por regressões diversas. É comum que a criança faça reinvindicações maternas na tentativa de busca de contato e de ser objeto exclusivo de amor dos pais. Para as autoras, trata-se de um movimento de reparação de um objeto bom de apego primário. O relato aponta para a sensibilidade de Julia diante das necessidades de Ana. Isso só foi possível por ela ter entrado em um estado de atenção, sendo capaz de oferecer à Ana o espaço para reviver e elaborar situações do seu passado. Esse estado pode ser compreendido como o período de preocupação materna primária (Winnicott, 2000/1956). Para o autor, esse período se caracteriza pela sensibilização exacerbada iniciada no final da gravidez e se estendendo até algumas semanas após o nascimento. A saúde psicológica e física do bebê depende da capacidade de a mãe entrar nesse estado de regressão. Durante o período de preocupação materna primária ocorre uma identificação sutil da mãe com o seu bebê, possibilitando que ela compreenda as suas manifestações sensoriais e seus conteúdos pré-verbais.

Encontrando-se em um momento de extrema sensibilidade, a mãe conseguirá entender as diversas necessidades de seu bebê e atender a elas- sono, fome, frio, entre outros. Inicialmente, os cuidados estão circunscritos às necessidades corporais, mas, pouco a pouco, abarcam também as necessidades do ego. Ao adaptar-se às necessidades de seu bebê, ele, paulatinamente, se desenvolve e vai obtendo um sentimento de segurança.

Os pais que possuem sensibilidade adequada serão capazes de compreender as situações de acordo com a perspectiva do filho, se antecipando aos sinais do bebê, interpretando-os corretamente e respondendo de forma rápida e satisfatória (Ochoa-Torres \& Lelong, 2006). No caso de Julia e Ana, nota-se que o alimento contém simbolismos importantes para a compreensão das necessidades da criança, conforme exemplificado na fala a seguir:

Ela chegou muito compulsiva de comer. Então, passou fome, né? Ela teve todos os perrengues no seu primeiro ano de vida. Então era uma compulsão, ela não podia ver resto de comida que ela pegava [...]É que eu não brigava porque estava comendo demais, nunca briguei porque tava comendo, só comecei a orientar, tipo assim, não precisa comer do chão, não precisa aceitar de estranho, né? Que é perigoso... Mas deixava ela comer e ela comia até passar mal. Demorei no processo de ensinar pra ela[...] Então, até em restaurante, levava... voltava, às vezes, com quentinha que tinha quase três caroços de arroz só (risos). Os garçons ficavam olhando e eu: "Vou levar pra casa, entendeu? Ela precisava entender. $E$ aí ela olhava assim, muitas vezes nem comia no dia seguinte... E aí, chegava no dia seguinte: "Você quer comer aquilo ou quer 
comer a comida que a mamãe fez?" "Ah, quero comer a que a mamãe fez".

Nota-se aqui o alimento como símbolo de afeto. Para Winnicott (2000/1945), a alimentação da criança é referida à relação mãe-bebê e se torna uma das primeiras formas de pôr em prática o amor entre os dois. Julia, por estar vivenciando seu estado de preocupação materna primária, pôde atender às necessidades de Ana, colocandose como mãe suficientemente boa na relação. Na medida em que a mãe acolhe as necessidades do bebê, ele vivencia a integração das funções corporais, e, consequentemente, se estabelece uma unidade, permitindo-o constituir seu self de forma satisfatória e experienciar a continuidade do ser (Winnicott, 2000/1956). Ademais, o autor pontua que o desenvolvimento da confiança no ambiente em que a criança está inserida origina-se nas primeiras relações entre a mãe e seu bebê, proporcionando a ele o sentimento de segurança, regularidade e continuidade.

Podemos observar que Julia se mostrou sensível às necessidades de Ana devido ao fato de ter sido capaz de vivenciar plenamente a "preocupação materna primária" e, assim, se mostrar atenta ao que o passado poderia repercutir na construção do seu vínculo com Ana:

Ela viveu até um ano e nove meses, mais ou menos, com a família biológica. Passou alguns meses no hospital e depois foi pro abrigo. Ficou menos de um ano no abrigo. O que eu acho que gerou assim, muita insegurança. Então, nossa primeira, vamos dizer assim, não foi briga, nossa primeira bronca mais séria, né? Com a minha cara mais séria, ela na hora disse assim: "Você vai me abandonar?" Então criou essa insegurança nela... Você não usa algumas palavras, eu evito algumas palavras... Eu nunca falei quando ela fazia alguma pirraça na rua, igual mãe faz, assim: "Não vai vir não? Então vou embora!" Nunca falei isso, podia ser o que fosse, entendeu? [...]Mas na rua, falar: "Oh, tô indo embora e você vai ficar aí". Nunca falei porque vai trazer um sofrimento que já é, na verdade, pra qualquer criança, né? A mãe falar que vai embora, pra qualquer criança já é um sofrimento. Mas pra elas é maior ainda, porque já foram né? Outros já foram e nunca mais voltaram.

Esse movimento implica também em oferecer segurança frente às possíveis crises e testes que a família irá enfrentar, permitindo que estas aconteçam e que os membros da família demonstrem suas capacidades de sobreviver aos ataques vindos da criança (Levy \& Bittencourt, 2013). Julia descreve como foi lidar com os momentos de crise e de testagem de Ana: 
Então, aí agora... Um mês antes de terminar a adoção ela mandou essa: "Você não é minha mãe! Você não manda em mim!"... E a mãe precisa brigar e tem horas que a filha fala que não te ama, você é a bruxa e não levar isso pelo lado pessoal, né? Levar isso como uma reação normal da criança. Então sempre quis ter essa relação que ela possa ter a segurança de que eu vou estar sempre do lado dela, independente do que ela tomar de decisões na vida, ela ter eu como porto seguro, que é um pouco do que eu tenho com a minha mãe.

Evidencia-se nessa fala a necessidade de a criança retomar a confiança no ambiente. Para isso, precisará reviver o que Winnicott (1990/1963) denominou por ciclo benigno, ou seja, a partir da percepção do bebê de sua sequência de ataques direcionados ao corpo materno, ele experimenta o sentimento de culpa, não consciente, por sua agressividade e capacidade destrutiva. A partir desse sentimento, o bebê passará a se utilizar de movimentos reparatórios. Quando a mãe é capaz de acolher esses movimentos destrutivos seguidos da tentativa de reparação, por repetidas vezes, em um processo cíclico, ela possibilita ao seu bebê apropriar-se de seus impulsos, tornando-se capaz de seguir de maneira produtiva diante da vida. Dito de outro modo, a partir desse ciclo, a mãe demonstra para seu bebê que é capaz de sobreviver e permanecer viva, produzindo o sentimento de continuidade de existência e possibilitando ao bebê utilizar-se de sua destrutividade de maneira construtiva.

De acordo com Winnicott (2016/1987), o lar adotivo tem uma finalidade terapêutica capaz de proporcionar à criança a recuperação da privação sofrida anteriormente. Para o autor, inicialmente, a criança pode se adaptar rapidamente ao novo ambiente, porém, na medida em que adquire confiança nele, ela pode sentir raiva pelo fato de seu ambiente anterior ter fracassado. Nesse contexto, os pais adotivos podem se tornar alvo do ódio da criança. Porém, ao demonstrarem para ela a sua capacidade de absorver os sentimentos negativos e de sobreviver a eles e aos seus ataques, possibilitam que se estabeleça uma relação mais segura e menos idealizada com a criança.

\section{Considerações Finais}

A experiência da adoção mãe-filha de Julia e Ana se apresenta como um caso exemplar, delicado, processo permeado pelo cuidado e atenção. Denota a beleza e a sensibilidade de uma construção mútua em direção à vinculação parento-filial. Pode-se concluir que, neste 
caso, a adoção se tornou efetiva a partir da disponibilidade de Julia de compreender as necessidades de Ana e de atender às mesmas, dando um novo sentido para as vivências da menina. A compreensão das necessidades emocionais da criança só foi possível porque a mãe vivenciou plenamente a "preocupação materna primária", mesmo que em momento relativamente tardio do desenvolvimento infantil. Desta forma, Julia ofereceu o holding necessário para que Ana experimentasse a vivência de integração e a continuidade da existência.

O estudo do caso de Julia e Ana leva-nos a pensar em possibilidades de prevenção e intervenção, sobretudo no que diz respeito à preparação dos pais nos processos de adoção de crianças maiores. $O$ presente estudo aporta importantes subsídios aos profissionais de saúde que lidam com as vicissitudes da adoção tardia. Apontamos como limitações, por se tratar de um estudo de caso, a impossibilidade de generalização dessa experiência, haja vista a singularidade de cada caso. Contudo, ao se aprofundar em um estudo de caso como este, é possível acessar vivências subjetivas importantes no processo de construção do vínculo parento-filial.

Trata-se de um caso de adoção bem-sucedida no qual o vínculo parento-filial encontrou campo fértil para ser construído. Diante das especificidades de cada caso de adoção, é pertinente assinalar a singularidade das experiências. Essas crianças carregam experiências de rupturas ao longo de suas histórias que interferem na construção de novos laços. Desta forma, em alguma medida, o novo ambiente deve ser testado, principalmente para a criança assegurar-se quanto à sua estabilidade e confiabilidade. O ambiente opera como uma espécie de continente para as angústias, regressões e sentimentos de abandono da criança.

Os pais adotivos podem colaborar para a elaboração do que possa ter sido vivenciado como traumático ou ruim no passado da criança, legitimando o que houve de bom, auxiliando-a a recriar seu futuro e a se constituir enquanto sujeito no mundo. Neste cenário, os pais podem oferecer a possibilidade de uma construção mútua, que entrelaça histórias, ao mesmo tempo em que lhes propicia vivenciarem a parentalidade, em ambiente permeado por afeto e cuidado.

No caso de Julia, o novo ambiente foi capaz de se fazer permanente, compreendendo as vivências traumáticas e suprindo as necessidades de Ana. Assim, Julia possibilitou que Ana reparasse experiências de cuidado primitivo, favorecendo o sentimento de continuidade de existência no seio familiar que Ihe faltava. 


\section{Referências}

Dolto, F. (2008). Quando os filhos precisam dos pais. Respostas a consultas de pais com dificuldades na educação dos filhos. São Paulo: Martins Fontes. (Obra original publicada em 1977)

Eboli, N. M. G., Santos, P. L. dos, Carvalho, A. M. P., \& Pasian, S. R. (2015). Parentalidade adotiva e psicopatologia infantil: Uma revisão da literatura. Revista da SPAGESP, 16(1), 122-134.

Gomes, K. (2006). A adoção à luz da teoria winnicottiana. Winnicott e-prints, 1(2), 1-18. Recuperado de http://pepsic.bvsalud.org/scielo.php?script=sci_arttext\&pid=S1 679-432X2006000200005

Gomes, I. C., \& Levy, L. (2016). A psicanálise vincular e a preparação de crianças para a adoção: Uma proposta terapêutica e interdisciplinar. Contextos Clínicos, 9(1), 109-117. doi: 10.4013/ctc.2016.91.09.

Gondim, A. K., Crispim, C. S., Fernandes, F. H. T., Rosendo, J. C., Brito, T. M. C., Oliveira, U. B., \& Nakano, T. C. (2008). Motivação dos pais para a prática da adoção. Boletim de Psicologia, 58(129), 161-170. Recuperado de http://pepsic.bvsalud.org/pdf/bolpsi/v58n129/v58n129a04.pdf

Levinzon, G. K. (2018). Adoção e falso self: O dilema do "bom adotado". In G. K. Levinzon, \& Lisondo, A. D. (Orgs.), Adoção: Desafios da contemporaneidade (pp. 49-70). São Paulo: Blucher.

Levy, L., \& Bittencourt, M. I. G. D. F. (2013). A delicada construção de um vínculo de filiação: $O$ papel do psicólogo em processos de adoção. Pensando famílias, 17(1), 41-53.

Levy, L., \& Gomes, I. C. (2017). Grupos de preparação à adoção: Dos pretendentes às crianças. In T. Féres-Carneiro (Org.), Casal e família: teoria, pesquisa e clínica (pp.157-174). Rio de Janeiro: Editora PUC-Rio.

Machado, R. N., Féres-Carneiro, T., \& Magalhães, A. S. (2015). Parentalidade adotiva: Contextualizando a escolha. Psico PUCRS, 46(4), 442-451. doi:10.15448/19808623.2015.4.19862

Machado, R. N., Féres-Carneiro, T., Mello, R., \& Magalhães, A. S. (2017). Constituição da parentalidade adotiva: Vivências afetivas e sociais no processo de reconhecer-se mãe. In T. Féres-Carneiro (Org.), Casal e família: teoria, pesquisa e clínica (pp. 175-190). Rio de Janeiro: Editora Puc-Rio.

Morelli, A. B., Scorsolini-Comin, F., \& Santeiro, T. V. (2015). O "lugar" do filho adotivo na dinâmica parental: Revisão integrativa de literatura. Psicologia Clínica, 27(1), 175-194. doi:10.1590/0103-56652015000100010 
Ochoa-Torres, C., \& Lelong, I. (2006). A função parental: Uma abordagem a partir da teoria do apego. In L. Solis-Ponton, Ser pai, ser mãe, parentalidade: Um desafio para o terceiro milênio (pp. 123-131). São Paulo: Casa do Psicólogo.

Orionte, I., \& Souza, M. G. S. (2005). O significado do abandono para crianças institucionalizadas. Psicologia em Revista, 11(17), 2946.

Recuperado de http://periodicos.pucminas.br/index.php/psicologiaemrevista/ar ticle/view/218/228

Otuka, L. K, Scorsolini-Comin, F., \& Santos, M. A. (2012). Adoção suficientemente boa: Experiência de um casal com filhos biológicos. Psicologia: Teoria e Pesquisa, 28(1), 55-63. doi:10.1590/S0102-37722012000100007

Ozoux-Teffaine, O. (2004). De laséparation à lafiliation. Du couchant au levant, une nouvelle vie pour l'enfant en adoption tardive. In O. Ozoux-Teffaine (Org.), Enjeux de l'adoption tardive Nouveaux fondements pour la clinique (pp. 95-123). Ramonville Saint-Agne: Éditons Ères.

Peiter, C. (2011). Adoção, vínculos e rupturas: Do abrigo à família adotiva. São Paulo: Zagodoni.

Rossato, J. G., \& Falcke, D. (2017). Devolução de crianças adotadas: Uma revisão integrativa da literatura. Revista da SPAGESP, 18(1), 128-139. Recuperado de http://pepsic.bvsalud.org/scielo.php?script=sci_arttext\&pid=S1 677-29702017000100010\&lng=pt\&tIng=pt

Safra, G. (2004). O sofrimento humano e as fraturas éticas. In G. Safra (Org.), A poética na clínica contemporânea (pp. 127143). São Paulo: Ideias e Letras.

Sampaio, D. S., Magalhães, A. S., \& Féres-Carneiro, T. (2018). Pedras no caminho da adoção tardia: Desafios para o vínculo parento-filial na percepção dos pais. Temas em Psicologia, 26(1), 311-324. doi:10.9788/TP2018.1-12Pt.

Sequeira, V. C., \& Stella, C. (2014). Preparação para a adoção: Grupo de apoio para candidatos. Psicologia: Teoria e Prática, 16(1), 69-78. doi:10.15348/1980-6906.

Silva, M. P. O. (2018). Adoção: Tempo de espera e mudança de perfil dos habilitados. In Levinzon, G. K. \& Lisondo, A. D. (Orgs.), Adoção: desafios da contemporaneidade (pp. 117-136). São Paulo: Blucher.

Stake, R. E. (2016). A arte da investigação com estudos de caso. Lisboa: Fundação Calouste Gulbenkian.

Verceze, F. A., Silva, J. M., de Oliveira, K. M., \& Sei, M. B. (2015). Adoção e a psicoterapia familiar: Uma compreensão winnicottiana. Revista da SPAGESP, 16(1), 92-106. Recuperado de 
http://pepsic.bvsalud.org/scielo.php?script=sci_arttext\&pid=S1 677-29702015000100008

Weber, L. N. D. (1996). Famílias adotivas e mitos sobre o laço de sangue. Jornal Contato CRP, 8(79). Recuperado de: http://www.nac.ufpr.br/wpcontent/uploads/2016/07/1996_Familias_adotivas_e_mitos_sob _relacoes_de_sangue.pdf

Winnicott, D. W. (1947). O ódio na contratransferência. In D. W. Winnicott, Da Pediatria à Psicanálise: obras escolhidas (pp. 277-287). Rio de Janeiro: Imago.

Winnicott, D. W. (1990). O desenvolvimento da capacidade de se preocupar. In D. W. Winnicott, $O$ ambiente e os processos de maturação (pp. 70-78). Porto Alegre: Artes Médicas. (Obra original publicada em 1963)

Winnicott, D. W. (1990). Provisão para a criança na saúde e na crise. In I. C. S. Ortiz (Trad.), O ambiente e os processos de maturação: Estudos sobre a teoria do desenvolvimento emocional (pp. 62-69). Porto Alegre: Artes Médicas. (Obra original publicada em 1962)

Winnicott, D. W. (1997). A adolescência das crianças adotadas. In M. A. V. Veronese, (Trad.), Pensando sobre crianças (pp. 131140). São Paulo: Artmed. (Obra original publicada em 1955)

Winnicott, D. W. (2000). Desenvolvimento emocional primitivo. In Da pediatria à psicanálise: Obras escolhidas (pp. 218-232). Rio de Janeiro: Imago. (Obra original publicada em 1945)

Winnicott, D. W. (2000). Preocupação materna primária. In D. W. Winnicott, Da Pediatria à Psicanálise: obras escolhidas (pp. 399-405). Rio de Janeiro: Imago. (Obra original publicada em 1956)

Winnicott, D. W. (2001). A família e o desenvolvimento individual. São Paulo: Martins Fontes. (Obra original publicada em 1965)

Winnicott, D. W. (2016). Privação e delinquência. São Paulo: Martins Fontes. (Obra original publicada em 1987)

\section{Endereço para correspondência \\ Débora Sampaio}

Pontifícia Universidade Católica do Rio de Janeiro

Rua Marquês de São Vicente, 225, Gávea, CEP 22453-900, Rio de Janeiro - RJ, Brasil

Endereço eletrônico: deborasampaio@rocketmail.com

\section{Cristina Ribeiro Dantas}

Pontifícia Universidade Católica do Rio de Janeiro

Rua Marquês de São Vicente, 225, Gávea, CEP 22453-900, Rio de Janeiro - RJ, Brasil

Endereço eletrônico: c.r.dantas@hotmail.com 


\section{Andrea Seixas Magalhães}

Pontifícia Universidade Católica do Rio de Janeiro

Rua Marquês de São Vicente, 225, Gávea, CEP 22453-900, Rio de Janeiro - RJ, Brasil

Endereço eletrônico: andreasm@puc-rio.br

\section{Terezinha Féres-Carneiro}

Pontifícia Universidade Católica do Rio de Janeiro

Rua Marquês de São Vicente, 225, Gávea, CEP 22453-900, Rio de Janeiro - RJ, Brasil

Endereço eletrônico: teferca@puc-rio.br

Recebido em: 17/01/2019

Aceito em: $25 / 07 / 2019$

\section{Notas}

* Doutoranda em Psicologia Clínica pela PUC-Rio. Professora no curso de graduação em Psicologia na Unigranrio e no Centro Universitário Celso Lisboa.

** Pós-doutoranda em Psicologia Clínica na PUC-Rio. Professora do Curso de Especialização em Psicoterapia de Família e Casal da PUC-Rio.

*** Professora Associada do Departamento de Psicologia da PUC-Rio. Especialista em Psicoterapia de Família. Bolsista de Produtividade em Pesquisa CNPq.

**** Professora Titular do Departamento de Psicologia da PUC-Rio. Especialista em Psicoterapia de Família. Bolsista de Produtividade em Pesquisa CNPq.

Financiamento: CAPES (2016)

Este artigo de revista Estudos e Pesquisas em Psicologia é licenciado sob uma Licença Creative Commons Atribuição-Não Comercial 3.0 Não Adaptada. 